\title{
A Wi-Fi Based Smart Irrigation Monitoring for an Agricultural Environment
}

\author{
Nikhil Patankar a,1, Manoli Charmal ${ }^{\text {a }}$, Nikhil Bhaskar ${ }^{\text {a }}$, Swati Janrao ${ }^{\text {a }}$, Aniket Kamble ${ }^{\mathrm{a}}$ \\ ${ }^{a}$ Dept. Of Information Technology Sanjivani College of Engineering, Kopargaon-423601 (MH), India
}

\begin{abstract}
A producer who controls irrigation using a smartphone. A firebase that uses weather data to predict when to water crops. Sensors that read how much water is in the soil. From water availability and unpredictable weather patterns to regulations from outside entities, it can be a challenge to irrigate crops. Nowadays IoT has different solutions to overcome with this kind of problem. The particular research targeted successfully by development effected system using NodeMCU, Sensors, firebase, and assertive application. These tools which could conserve a good amount of water, it will become vital to success as the population groves and water availability dries up. The tool works by helping farmers with limited irrigation capacity determine the best time to water their crops. The main ai $\mathrm{m}$ of automating the system is to provide a certain amount of water required by crops by monitoring the moisture of soil and surrounding temperature. This obtains with the help of sensors and NodeMCU for interfacing their values. The values are displayed on a mobile application in real-time using Google's firebase. Irrigation using IoT is a key component of precision agriculture. By changing manual irrigation with automatic valves and systems reduces the human error. Farmer can monitor his crop yield from anywhere at any time.
\end{abstract}

Index Terms-Iot, NodeMCU, Firebase, wireless sensors

\section{Introduction}

India's agricultural sector is on the cusp of a breakthrough technological transformation. After decades of evolution, starting from mechanization and the Green Revolution, disruptive technologies have ushered in Precision Agriculture. Digital Farming is much required in the Indian context as by 2050, India will have an estimated 1.64 billion population1 and will need 333 million tonnes of annual food grain production. Climate change aggravates the situation and threatens to reduce yields of major crops by 25The Wi-Fi-based smart an irrigation system is an IoT based device that monitors the different aspects like soil moisture, Water level, Humidity at a threshold value and then it sends a message to the monitoring part of the proposed system. It provides water supply to crop at the right time, in the right quantity, and at the right place in crop field which plays a vital role in the plant's growth. Monitoring a water level is also a challenging task, especially the management becomes difficult during the shortage of water which may otherwise damage the crop. Using sensors like moisture, temperature, etc.

${ }^{1}$ Nikhil Patankar, Dept. Of Information Technology Sanjivani College of Engineering, Kopargaon Email: patankarnikhilit@sanjivani.org.in. 
water level can be managed easily by analyzing the condition of soil and climate. The sensors which are used in the proposed system like soil moisture sensors smartly monitor the soil moisture and depending on that data, the field irrigated automatically with fewer human mediate

\section{Literature Survey}

This proposed system is a smart irrigation strategy using the IoT domain. In this system the sensors are located in the agricultural sector, measuring the soil wetness content, water level of the tank, and the mobile app interface to analyze data and act on results obtained to perform the desired action [1]. This particular paper represents smart irrigation using WSN and water pumps. The proposed system supports aggressive water management for the land. The database connected to the web server analyzes the data which is set at threshold values that are set by the farmer. If the values do not compare with the specified values aware the farmer of the water requirement [2]. The paper is aimed to provide valuable information related to automated smart irrigation. This proposed system reads the Temperature and Humidity, Water level, and soil moisture of soil at a specified value. The main aim is to maintain the nutrient balance of the soil for the overall development of a plant [3]. This paper presents the wireless nodes of an intelligent agricultural system to monitor and controlling crop production framework based on IoT. The sensor node is stored in an agricultural and battery environment with electrical power. The control node is located on the monitoring side. It can look at and offer different prices so that the farmer can easily determine the yield status of their crop as long as there is internet availability [4].

\section{Components and Technology used}

\section{A. NodeMCU (ESP8266)}

The NodeMCU is an open-source firmware that is built on-chip called ESP8266. It contains the element like CPU, RAM, Wi-Fi and even modern operating system and SDK,NodeMCU refers to the firmware which is the set of instructions programmed on a hardware device. The hardware prototype used on NodeMCU consists of the dual-in-line package with an integrated USB controller onboard with an antenna and MCU.

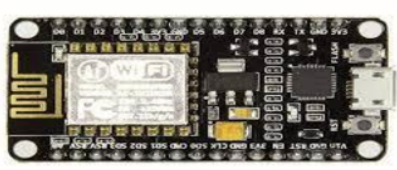

Figure 1. NodeMCU

\section{B. DHT11 Sensor}

DHT11 is used to measure relative digital signal as an output of temperature and humidity as serial data. customized digital module technology, as well as heat and 
humidity technology, are used to take care of products that have high reliability and good appropriate balance. The sensor incorporates the opposite sensor of the wet part and the NTC temperature measuring device and is connected by an efficient 8-bit microcontroller.

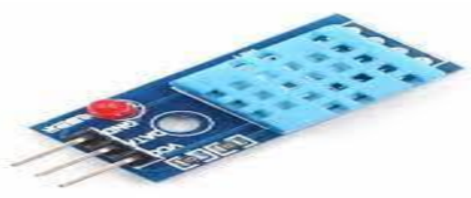

Figure 2. DHT11 Sensor

\section{Soil moisture sensor}

Soil wetness sensors compute the presence of water in the soil. It looks like a fork-shaped probe with two-conductor performing as a variable resistor. whose resistance changes concerning the water content present in the soil. the better conductivity means that the amount of water present in the soil is decent this result shows in lower resistance. similarly with the poor conductivity which means the volume of water present in the soil is less it will result in case of higher resistance. soil wetness sensor provides both analog and digital output. An output voltage produced by the sensor in terms of resistance, by measuring it helps to determine the wetness level of the soil.

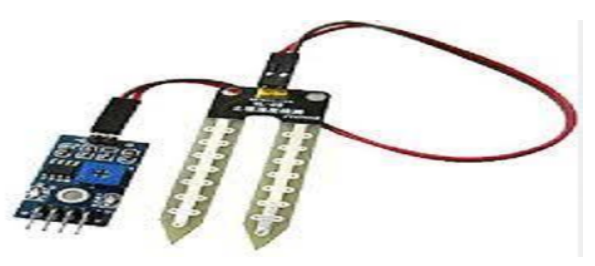

Figure 3. Soil moisture sensor

\section{Relay Module}

A relay is an electronic appliance.it mainly uses to operate as a controlled system that is input circuit or output circuit. It is always working as a control unit for the automatic circuit. Simply, it is an actuator that controls a very high circuit concerning a low current signal. when the relay senses the fault current flowing through the system, it electrifies the electromagnetic field this magnetic field is responsible for opening and closing the connection. hence it plays a vital role in systems implementation for sustain the flow of current 


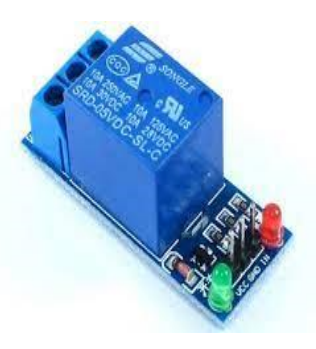

Figure 4. Relay Module

\section{E. Motor Pump}

A DC motor is a continuous actuator that converts energy in the form of mechanical energy via electrical energy. The DC motor operated on direct current. A DC motor consists of two parts, A "Stator" is the stationary part and a "Rotor" is the rotating part. The Relay acts as a switching and controlling unit for the motor pump.

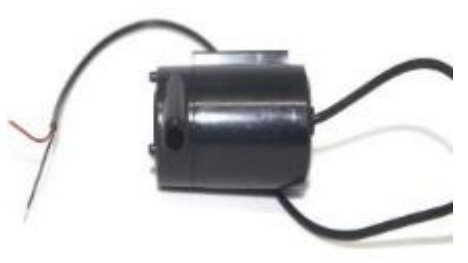

Figure 5. Motor pump

\section{F. Breadboard}

The breadboard is the basis for building electronic prototyping. Originally, the term referred to a piece of literal bread, a piece of polished wood used to cut bread. In the 1970s a solderless breadboard (a.k.a.boardboard, a terminal array board) was discovered and nowadays the term "breadboard" is often used to refer to these. This makes it easy to use in building temporary prototypes and attempting circuit construction.

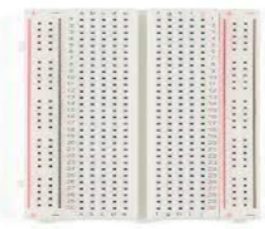

Figure 6. Breadboard 


\section{G. Connecting Wires}

A jump wire (also called jumper wire, or jumper) is an associate electrical wire, or cluster of them during a cable with an instrumentality or pin at every finish point that is generally accustomed to interconnect the parts of a breadboard or different model. These jump wires mainly established the connection between the NodeMCU and various sensors which are used in the system. The jump wire is used to connect point-to-point connections on the breadboard.

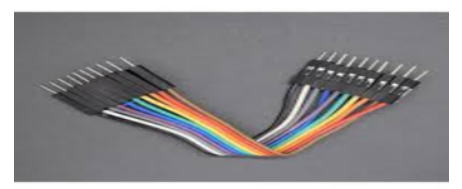

Figure 7. Connecting wires

\section{H. Float Sensor}

A floating sensor is a type of standard sensor, a tool used to determine the level of water inside a tank. We can say it as a level sensor as it is used to measure the liquid level of the tank. water level float detector or float switches, use the principle of fabric buoyancy (differential densities) to follow fluid levels.

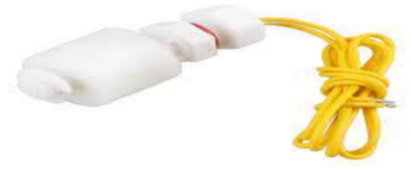

Figure 8. water level float sensor

\section{Google Firebase Cloud}

The firebase real-time database continuously monitors the real-time data flow of the system. which is stored on a cloud-hosted database in JSON format. The firebase uses data synchronization whenever data changes. It integrates well native with ios , android as well as web. Firebase automatically scales when there's high traffic and scales down when not in use so it is cost-effective it provides security over the data using authentication, we authenticate firebase with firebase id and secret key. Firebase Realtime Database lets allow you to build an interactive application that securely gets access from the database at the user side.

\section{Firebase}




\section{J. Arduino IDE}

Arduino Integrated Development Environment (IDE) is an open-source software platform used for writing and compiling the code in $\mathrm{c}$ and $\mathrm{c}++$ languages. The set of instructions(code) in the Hex file format is uploaded on a microcontroller. It is having a two-part Editor and compiler editor responsible for writing the code and compiler used to compile the uploaded code

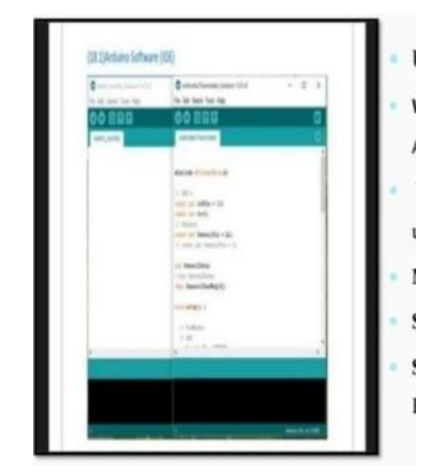

Figure 10. Arduino IDE

\section{Proposed System}

As mentioned in the introduction the implemented system helps the farmer to sustain the quality of the crop by an automated irrigation system. The proposed system is sensing the temperature and humidity, soil wetness content, and tank water level from the farm without any human interaction. The Proposed system used to sense the physical world data using wireless sensors are used in the area to get real-time data, a master node get the data from the sensor and transmit the data to the cloud section, Each node includes sensors like temperature, humidity, and soil moisture, are control by a microcontroller and for water pump relay is used and it works as an actuator. The data received from the sensor of each node is transmitted to the cloud section via NodeMCU. The firebase database represents the sensed data as a result. as per the threshold values defined in the algorithm based upon that motor, the pump is operated and we used an android application to deliver the information associated with the field to the remotely located farmer.

\section{The system consists of the following section.}

\section{A.Wireless sensor Node}

Figure 11 shows the overall system architecture of the proposed system that includes wireless sensors and the cloud section. The temperature and humidity sensor, float sensor, and soil wetness sensor are sensed real-time data. Data received from the 
sensors is processed by a micro-controller and transfer to the firebase database via NodeMCU for further Processing. The threshold values are set according to the crop that needs to be irrigated. The NodeMCU micro-controller works as firmware that is the programmable hardware device. The data obtained from sensors is further transferred to a cloud base database (firebase) via NodeMCU.

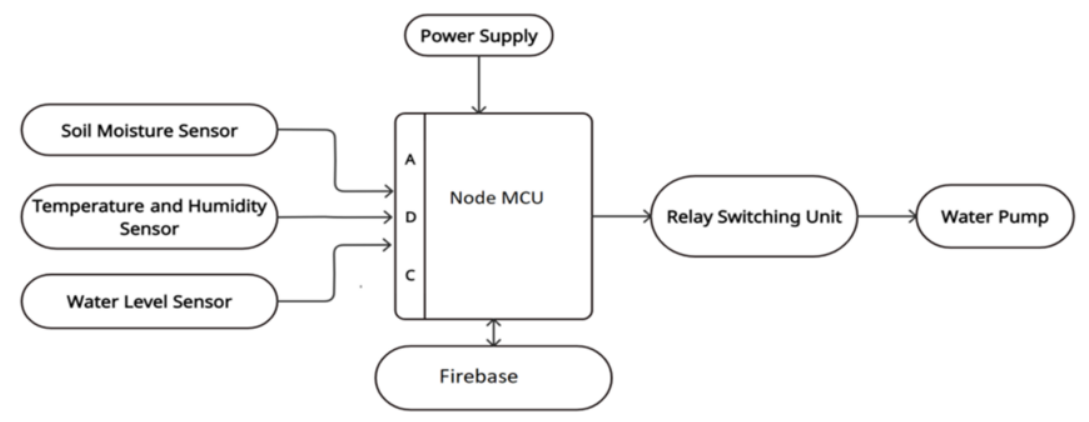

Figure 11. System Architecture

\section{B.Cloud section}

At cloud server which is nothing but the firebase used to monitor and store the real-time data. The farmer will Figure out the better decision for better crop yield based upon past data. Figure 12 shows the interaction between the microcontroller and the cloud server. The farmer will able to interact with the cloud server using the android and web application interface. The Decision of whether irrigation is on or off is based on comparisons between soil moisture values, air temperature values, the water level of the tank, and appropriate threshold values. The system controls irrigation according to a decision based on real-time parameters

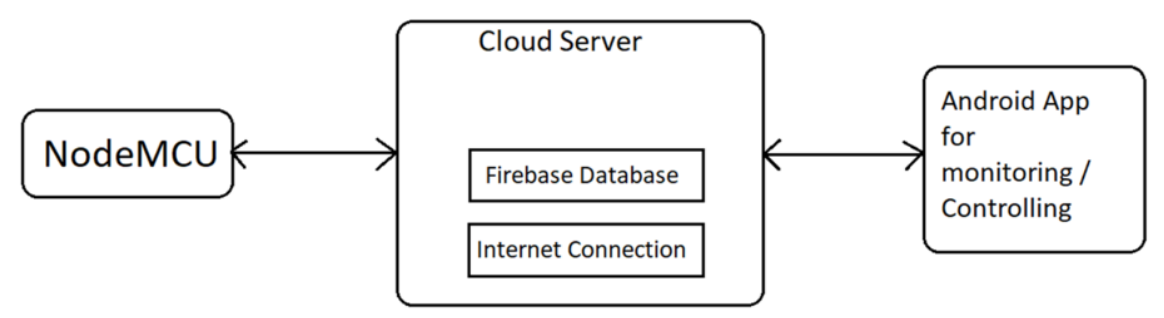

Figure 12. Cloud Server 


\section{System Implementation}

An algorithm designed for the proposed system as mentioned in Figure 13. All information obtained from various sensors and parameters is provided by the NodeMCU microcontroller as an analog input. The pre-determined value of the soil wetness sensor, as well as water height in the tank, is set in the microcontroller. When it exceeds a certain amount of water the irrigated plants are watered and once the required amount of water has been filled, they stop. The microcontroller transmits that information online via the IoT framework in form of the Wi-Fi module attached to it. As the system works itself the irrigation via the motor pump can be switch-on or switch-off with the information provided by the controller. This proposed Irrigation system is used to detect real-time. This method is designed to advance the automatic irrigation process without power by balancing the various boundaries associated with the field and thus improve irrigation.

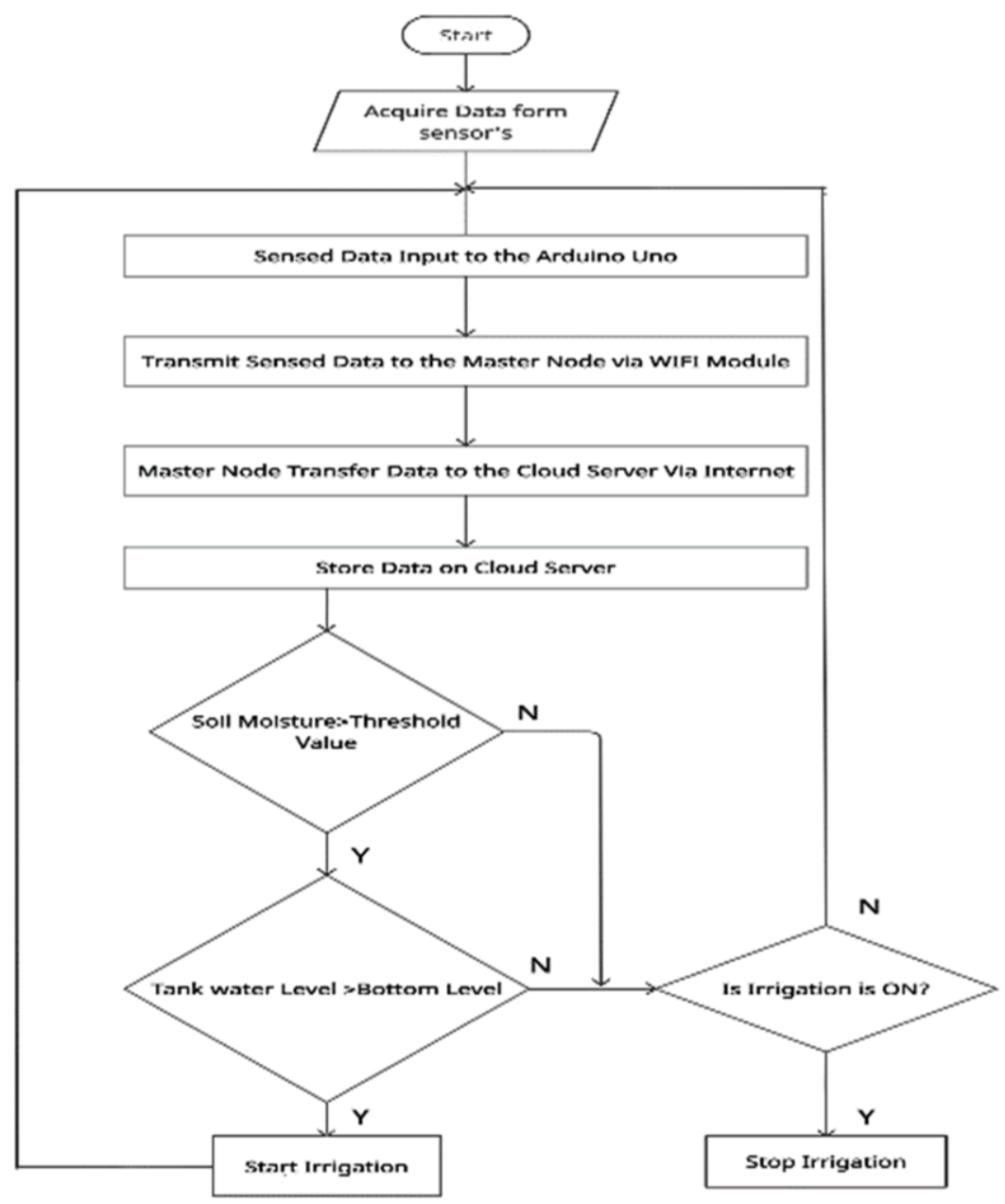

Figure 13. Algorithm of proposed system 


\section{Results}

A proposed irrigation system was tested on a plant in the garden. The water requirement of the plant is $600-800 \mathrm{~mm}$ per day and the soil temperature requirement is from $40 \mathrm{oC}-600 \mathrm{oC}$. In the Arduino code, the humidity and temperature range is set to 300-700 and 450-800 respectively (meaning the corresponding resistance value in digital format). In addition, the program appears to be cost-effective and has the potential to save water and reduce waste. it also indicates the level of water in the tank. In Figure 14 shows a mobile application developed using MIT app inventor which is used to monitor the environment of the area and control the water pump.

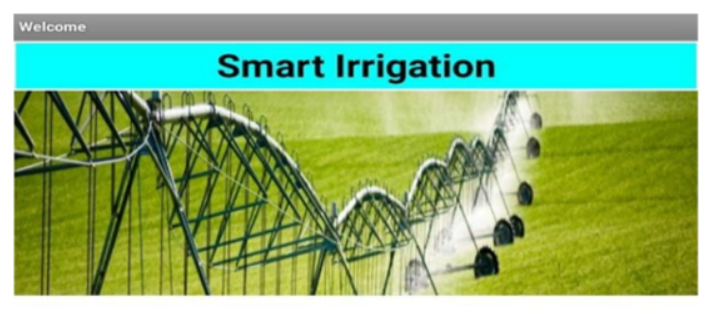

Temperature $\quad 32.80 \hat{A}^{\circ} \mathrm{C}$

Humidity $\quad 35.00 \%$

Soil Moisture $\quad-0.10 \%$

Water Level Low

Water Level is Low

Water Pump

Figure 14. Android application interface

\section{Conclusion}

The implementation of the proposed system is successfully tested. As a result of this system, it can measure soil moisture, Humidity, Temperature. Using this technology, it is become more efficient to solve farming problems like water shortage problems, soil moisture, and temperature. Farmer can monitor the crop from any place. By building an agriculture IoT platform to comprehensively monitor the growth status of crop it will help to solve the issues more effectively. This project uses a modern database like Google's firebase for fetching data from sensors. Also further proposed 
system can also monitor water level by water level sensors it would lead system to have efficient use of water to the crop. Not only this it will also control the consumption of water for irrigation of the field. The on-field research tells us that the results are executed for the better crop and the lessening of water. The system decreases the manpower necessary to field.

\section{References}

[1] Shweta B. Saraf Dhanashri H. Gawali "IoT Based Smart Irrigation Monitoring And Controlling System"2017 2nd IEEE International Conference On Recent Trends in Electronics Information Communication Technology (RTEICT), May 19-20, 2017, IndiaPavithra D.M.S .Srinath "GSM based Automatic Irrigation Control System "for Efficient use of Resources and crop Planning by using an Android Mobile "IOSR Journal of Mechanical and Civil Engineering (IOSR-JMCE), e-ISSN: 22781684,p-ISSN: 2320-334X, Volume 11, Issue 4 Ver. I (Jul- Aug. 2014), PP 49-55.

[2] Pavithra D.M.S .Srinath "GSM based Automatic Irrigation Control System "for Efficient use of Resources and crop Planning by using an Android Mobile "IOSR Journal of Mechanical and Civil Engineering (IOSR-JMCE), e-ISSN: 2278-1684,p-ISSN: 2320-334X, Volume 11, Issue 4 Ver. I (JulAug. 2014), PP 49-55.

[3] Sensor based Automated Irrigation System with IOT" International Journal of Computer Science and Information Technologies, ISSN: 0975-9646, Vol. 6 (6) 2015, 5331-5333.

[4] G. H. E. L. de Lima, L. C. e Silva and P. F. R. Neto, "WSN as a Tool for Supporting Agriculture in the Precision Irrigation," 2010 Sixth International Conference on Networking and Services, Cancun, 2010, pp. 137-142.

[5] Kumar, A., Vengatesan, K., Vincent, R., Rajesh, M., \& Singhal, A. (2019). A novel Arp approach for cloud resource management. International Journal of Recent Technology and Engineering (IJRTE), 7(6).

[6] A. Kumar, K. Kamal, M. O. Arshad, S. Mathavan and T. Vadamala, "Smart irrigation using low-cost moisture sensors and XBee-based communication," IEEE Global Humanitarian Technology Conference (GHTC 2014), San Jose, CA, 2014, pp. 333-337 Sukru Ozan, "A Case Study on Customer Segmentation by using Machine Learning Methods", IEEE, Year: 2018 